\title{
Deployment of a sequential two-photon laser-induced fluorescence sensor for the detection of gaseous elemental mercury at ambient levels: fast, specific, ultrasensitive detection with parts-per-quadrillion sensitivity
}

\author{
D. Bauer ${ }^{1}$, S. Everhart ${ }^{1}$, J. Remeika ${ }^{1}$, C. Tatum Ernest ${ }^{1, *}$, and A. J. Hynes ${ }^{1}$ \\ ${ }^{1}$ Division of Marine and Atmospheric Chemistry, Rosenstiel School of Marine and Atmospheric Science, \\ University of Miami, 4600 Rickenbacker Causeway, Miami, Florida 33149, USA \\ * currently at: Atmospheric Chemistry Department, Max Planck Institute for Chemistry, Hahn-Meitner-Weg 1, \\ 55128 Mainz, Germany \\ Correspondence to: A. J. Hynes (ahynes@ rsmas.miami.edu)
}

Received: 21 May 2014 - Published in Atmos. Meas. Tech. Discuss.: 6 June 2014

Revised: 17 September 2014 - Accepted: 30 September 2014 - Published: 8 December 2014

\begin{abstract}
The operation of a laser-based sensor for gasphase elemental mercury, $\operatorname{Hg}(0)$, is described. It utilizes sequential two-photon laser excitation with detection of blueshifted laser-induced fluorescence (LIF) to provide a highly specific detection scheme that precludes detection of anything other than atomic mercury. It has high sensitivity, fast temporal resolution, and can be deployed for in situ measurements in the open atmosphere with essentially no perturbation of the environment. An ambient sample can also be pulled through a fluorescence cell, allowing for standard addition calibrations of the concentration. No type of preconcentration is required and there appears to be no significant interferences from other atmospheric constituents, including gas-phase oxidized mercury species. As a consequence, it is not necessary to remove oxidized mercury, commonly referred to as reactive gaseous mercury (RGM), from the air sample. The instrument has been deployed as part of an instrument intercomparison and compares well with conventional instrumentation that utilizes preconcentration on gold followed by analysis using cold-vapor atomic fluorescence spectroscopy (CVAFS). Currently, the achievable detection sensitivity is $\sim 15 \mathrm{pg} \mathrm{m}^{-3}\left(\sim 5 \times 10^{4}\right.$ atoms $\left.\mathrm{cm}^{-3}, \sim 2 \mathrm{ppq}\right)$ at a sampling rate of $0.1 \mathrm{~Hz}$, i.e., averaging 100 shots with a $10 \mathrm{~Hz}$ laser system. Preliminary results are described for a $50 \mathrm{~Hz}$ instrument that utilizes a modified excitation sequence and has monitored ambient elemental mercury with an effective sampling rate of $10 \mathrm{~Hz}$. Additional work is required to
\end{abstract}

produce the precision necessary to perform eddy correlation measurements. Addition of a pyrolysis channel should allow for the measurement of total gaseous mercury (TGM) and hence RGM (by difference) with good sensitivity and time resolution.

\section{Introduction}

A detailed understanding of the biogeochemical cycling of mercury and the routes to the production of organomercury compounds in ecosystems is a critical issue from a human health perspective. Direct exposure to mercury is primarily through the ingestion of dimethyl mercury from fish consumption; however an understanding of the overall budget and mechanism of chemical transformation of mercury in both its elemental and combined forms is critically important. (U.S. EPA, 2000; Mergler et al., 2007; UNEP, 2008, Diez, 2009). Wet or dry deposition of oxidized mercury is an important step in a complex process that involves both chemistry and microbiology and eventually produces alkyl mercuric compounds. Regulation of anthropogenic mercury sources in the US has almost eliminated emissions from municipal waste combustors and medical waste incinerators and the new "Mercury and Air Toxics Standards" (MATS) will require reductions in mercury emissions from coal-burning power plants (U.S. EPA, 2011). On an international scale the 
United Nations Environment Programme has been focused on developing an increased understanding of the global impact of atmospheric mercury (UNEP, 2013). Reductions in mercury emissions have been the focus of global negotiations that have led to the Minimata Convention on Mercury, a multilateral environmental agreement that has been signed by 97 countries (UNEP, 2014). Nevertheless, these developments take place in a situation in which our overall understanding of the chemistry of atmospheric mercury transformation is limited (Hynes et al., 2008; Subir et al., 2011, 2012; Gustin and Jaffe, 2010). In the absence of a detailed understanding of the atmospheric cycling of mercury, it is quite possible that the desired environmental results will not be attained. For example, emission controls in the USA are designed to try to reduce the wet and dry deposition that ultimately produces increased mercury concentrations in aquatic environments. If this deposition is controlled by oxidation of the global mercury pool, rather than by US anthropogenic emissions, then emission reductions will not decrease deposition.

The typical background concentrations of $\operatorname{Hg}(0)$ in unpolluted environments range from 1.5 to $2 \mathrm{ng} \mathrm{m}^{-3}$, where $1 \mathrm{ng} \mathrm{m}^{-3}$ is $\sim 3 \times 10^{6}$ atoms cm${ }^{-3}$ or $\sim 120 \mathrm{ppq}$ (parts per quadrillion), and reactive gaseous mercury (RGM) is thought to be typically less than $10 \%$ of this value; hence atmospheric measurements represent a significant challenge in ultratrace analytical chemistry (Gustin and Jaffe, 2010). It is also important to note that the chemical speciation of oxidized mercury has not been established. Current approaches to the measurement of both elemental and oxidized mercury at ambient levels rely exclusively on instruments that use preconcentration on gold followed by analysis using coldvapor atomic fluorescence spectroscopy (CVAFS). The issues and problems associated with this approach are discussed by Gustin and Jaffe (2010) and include the question of the extent to which CVAFS instruments are measuring $\mathrm{Hg}(0)$ or total gaseous mercury (TGM) or something intermediate between the two. In addition, the necessity to preconcentrate requires a sampling time of minutes for $\mathrm{Hg}(0)$ and precludes fast measurements. The current approach to measurement of RGM relies almost exclusively on sampling on $\mathrm{KCl}$-coated annular denuders followed by pyrolysis and CVAFS analysis of the $\mathrm{Hg}(0)$ produced by RGM decomposition (Landis et al., 2002).

The development of a fast in situ sensor capable of measuring $\operatorname{Hg}(0)$ at ambient levels is a critical research need. Such a sensor can independently verify the performance of the CVAFS instruments. In addition, this type of sensor would offer the possibility of measuring mercury fluxes using a direct micro-meteorological approach: the eddy correlation technique.

We have developed a laser-based sensor for the detection of gas-phase elemental mercury, $\mathrm{Hg}(0)$, using sequential two-photon laser-induced fluorescence (2P-LIF). The instrument is capable of fast in situ measurement of $\mathrm{Hg}(0)$ at ambient levels. By incorporating pyrolysis to convert RGM to $\mathrm{Hg}(0)$, it is possible to measure TGM, and hence RGM by difference. Under atmospheric conditions, the detection of $\mathrm{Hg}(0)$ is unambiguous since the sensor can not detect an oxidized mercuric species, irrespective of its chemical speciation, and there are no known atmospheric interferences, i.e., atoms or molecules, that can produce a false positive or artifact signal.

In a prior study we examined four variants of $2 \mathrm{P}-\mathrm{LIF}$ detection of $\operatorname{Hg}(0)$ and performed a detailed laboratory characterization of the spectroscopic characteristics of the most sensitive variant (Bauer et al., 2002, 2003). In this work we describe the performance of a field instrument that uses this approach and was deployed as part of the RAMIX (Reno Atmospheric Mercury Intercomparison Experiment) intercomparison of mercury detection instruments (Gustin et al., 2013). We also show preliminary results from a "secondgeneration" 2P-LIF system that utilizes a different excitation scheme.

\section{Principles of operation}

It is instructive to compare the 2P-LIF approach with CVAFS instruments currently used to monitor $\mathrm{Hg}(0)$ as exemplified by the Tekran 2537 mercury vapor analyzers (Tekran, 2001). In CVAFS systems, air is pulled through a gold trap that removes gas-phase mercury, forming an amalgam. After a period of sampling the gold trap is flushed with argon and then heated, releasing $\operatorname{Hg}(0)$, which flows into a fluorescence cell. A mercury discharge lamp is used to induce fluorescence using the $6^{3} \mathrm{P}_{1}-6^{1} \mathrm{~S}_{0}$ transition at $253.7 \mathrm{~nm}$ with detection of resonance fluorescence using a photomultiplier tube (PMT). The key features of the instrument are (i) the gold amalgamation step that selectively removes and preconcentrates gas-phase mercury and (ii) the detection of $\operatorname{Hg}(0)$ via resonance fluorescence in the presence of an inert gas that does not quench the $6^{3} \mathrm{P}_{1}$ excited state. The removal of air and use of an inert gas is critical for establishing high sensitivity because $\mathrm{O}_{2}$ is an extremely efficient quencher of the $6^{3} \mathrm{P}_{1}$ excited state. The $6^{3} \mathrm{P}_{1}$ state has a radiative lifetime of $119 \mathrm{~ns}$ and the quenching rate coefficient with $\mathrm{O}_{2}$ is $3.6 \times 10^{-10} \mathrm{~cm}^{3}$ molecule ${ }^{-1} \mathrm{~s}^{-1}$ (Michael and Suess, 1974; Breckenridge and Umemoto, 2007). The fluorescence efficiency in air at atmospheric pressure can be calculated using the Stern-Volmer relationship and gives a fluorescence efficiency of $4.7 \times 10^{-3}$ and an effective radiative lifetime of $0.56 \mathrm{~ns}$. It should be noted that the quenching efficiency of $\mathrm{N}_{2}$ is approximately 2 orders of magnitude lower than that of $\mathrm{O}_{2}$ and that it contributes little to quenching in spite of its higher partial pressure (Deech et al., 1971). Commercial instruments utilizing gold amalgamation typically have detection sensitivities of $0.1 \mathrm{ng} \mathrm{m}^{-3}$ based on sampling times of 2.5-5 min. Based on these considerations, it should be clear that while the CVAFS instrumentation is suitable for ambient 
monitoring, it is not capable of fast in situ measurements of $\mathrm{Hg}(0)$.

The 2P-LIF instrument utilizes two tunable lasers to sequentially pump two atomic transitions in $\mathrm{Hg}(0)$ followed by the detection of blue-shifted LIF. The instrument has been deployed in two excitation configurations and the relevant atomic transitions are shown in Fig. 1. In the "firstgeneration" system the first tunable laser operates at a fundamental wavelength of $507.3 \mathrm{~nm}$ and is frequency doubled to produce $253.7 \mathrm{~nm}$ exciting the $\mathrm{Hg} 6{ }^{3} \mathrm{P}_{1}-6^{1} \mathrm{~S}_{0}$ transition. This is followed by excitation with a second laser at $407.8 \mathrm{~nm}$ to the $7^{1} \mathrm{~S}_{0}$ level via the $7^{1} \mathrm{~S}_{0}-6^{3} \mathrm{P}_{1}$ transition. Both radiative decay and collisional energy transfer produce population in the $6^{1} \mathrm{P}_{1}$ level. Blue-shifted fluorescence is then observed on the strong $6{ }^{1} \mathrm{P}_{1}-6^{1} \mathrm{~S}_{0}$ transition at $184.9 \mathrm{~nm}$ using a solar-blind PMT. The first-generation system was deployed at RAMIX. In an effort to investigate the possibility of increasing sensitivity for high-frequency measurements, we have made preliminary measurements using a secondgeneration system. The second-generation system uses the same $\mathrm{Hg} 6^{3} \mathrm{P}_{1}-6{ }^{1} \mathrm{~S}_{0}$ transition for the initial excitation, and this is followed by excitation of the $6^{3} \mathrm{D}_{1}-6^{3} \mathrm{P}_{1}$ transition at $313.2 \mathrm{~nm}$. This fluoresces at $578.9 \mathrm{~nm}$ via the $6^{3} \mathrm{D}_{1}-6^{1} \mathrm{P}_{1}$ transition and again produces population in the $6^{1} \mathrm{P}_{1}$ level. Blue-shifted fluorescence is again observed on the strong $6^{1} \mathrm{P}_{1}-6^{1} \mathrm{~S}_{0}$ transition at $184.9 \mathrm{~nm}$ using a solar-blind PMT. The excitation schemes involving sequential excitation of two atomic transitions, followed by detection of the emission from a third, are extremely specific and preclude detection of anything other than $\mathrm{Hg}(0)$. In typical single-photon fluorescence systems, including CVAFS, sensitivity is normally limited by the detection of scattered excitation light that occurs at, or is red-shifted relative to, the excitation wavelength. 2P-LIF is detected at $184.9 \mathrm{~nm}$ with a solar-blind PMT that has a negligible quantum efficiency above $240 \mathrm{~nm}$, resulting in no detection of the 407.8 and $313.2 \mathrm{~nm}$ excitation scatter and minimal response to the $253.7 \mathrm{~nm}$ scatter. This leads to the very high sensitivity. A significant added advantage is that the presence of atmospheric aerosols does not significantly degrade detection sensitivity, so it is not necessary to pass the airflow through filters to remove particulates. In systems that utilize resonance fluorescence, even a small particulate loading can dramatically degrade sensitivity because of the increase in scattering of the excitation beam. Similarly, detection approaches using CRDS (cavity ringdown spectroscopy) require filtering because of the attenuation produced by aerosols. In the sequential two-photon system the increase in scatter of the 253.7 and $407.8 \mathrm{~nm}$ beams has little impact because these wavelengths are not detected by the PMT. In prior work we examined the linearity, saturation and spectroscopic characteristics of the 2P-LIF system using a high-power "laboratory" laser system consisting of a Nd:YAG laser, dye laser and optical parametric oscillator (Bauer et al., 2002, 2003). Comparison with a Tekran 2537 demonstrated that 2P-LIF is linear over a wide range

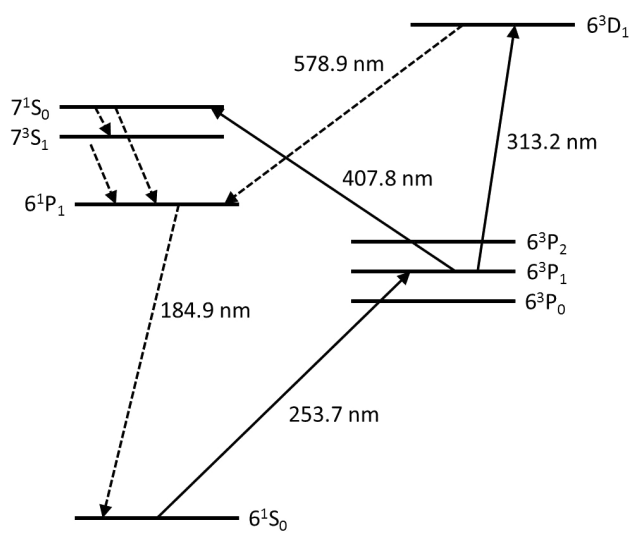

Figure 1. Atomic transitions for $\operatorname{Hg}(0)$ that were used in the firstand second-generation detection systems.

of $\operatorname{Hg}(0)$ concentrations and that the line widths of the excitation transitions were relatively broad. We also examined the saturation characteristics that show the relationship between the power of the excitation beams and the fluorescence signal. The challenge for the ambient environmental monitoring was to produce a relatively compact laser system that would operate reliably for extended periods of time in a mobile trailer.

\section{Description of the mobile instrument}

The complete 2P-LIF instrument package deployed for the RAMIX intercomparison was housed in a $20 \mathrm{ft} \times 8 \mathrm{ft}$ mobile laboratory. Figure 2 shows a block diagram of the experimental setup. A $4 \mathrm{ft} \times 10 \mathrm{ft}$ optic bench supported the laser systems, optics, and sample cells. The system configuration consisted of two dye lasers (Quanta Ray PDL-2) pumped by a single $10 \mathrm{~Hz}$ Nd:YAG laser (Quanta Ray GCR-16). The initial excitation and detection scheme, as discussed above, employed one photon each of 253.7 and $407.8 \mathrm{~nm}$ light for the sequential excitation of $\mathrm{Hg}(0)$ with the detection of fluorescence at $184.9 \mathrm{~nm}$. The third harmonic of the Nd:YAG laser was split and used to simultaneously pump the two dye lasers. The first laser, using Coumarin 500 dye, operated at a fundamental wavelength of $507.3 \mathrm{~nm}$ and was frequency doubled to produce the $253.7 \mathrm{~nm}$ excitation photon. The dye was dissolved in methanol with oscillator and amplifier concentrations of 400 and $95 \mathrm{mg} \mathrm{L}^{-1}$, respectively. The typical doubled dye laser output was $1 \mathrm{~mJ}$ pulse ${ }^{-1}$. The second dye laser, using Exalite 411 dye, operated at a fundamental wavelength of $407.8 \mathrm{~nm}$, generating the second excitation photon directly. The dye was dissolved in dioxane with oscillator and amplifier concentrations of 150 and $50 \mathrm{mg} \mathrm{L}^{-1}$, respectively. The typical dye laser output was $5 \mathrm{~mJ}$ pulse ${ }^{-1}$. In the secondgeneration system the second dye laser was pumped with the residual second harmonic of the Nd:YAG laser and used DCM dye. The dye was dissolved in methanol with oscillator 


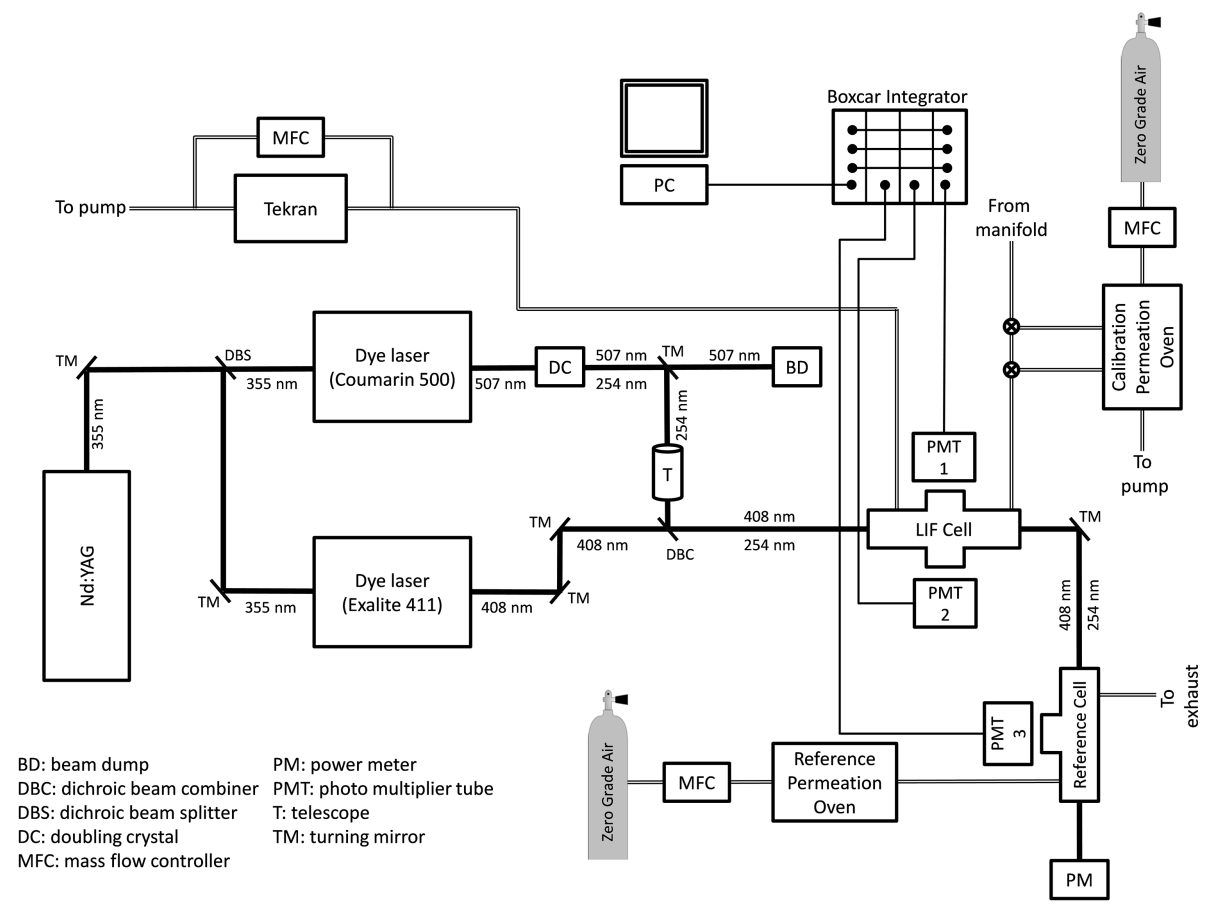

Figure 2. Block diagram of the "first-generation" 2P-LIF system deployed at RAMIX.

and amplifier concentrations of 170 and $24 \mathrm{mg} \mathrm{L}^{-1}$, respectively. The typical doubled dye laser output was $2 \mathrm{~mJ}$ pulse $^{-1}$ with $10 \mathrm{~Hz}$ pumping and $0.2 \mathrm{~mJ}$ pulse ${ }^{-1}$ with $50 \mathrm{~Hz}$ pumping. As noted above, the effective radiative lifetime of the $6^{3} \mathrm{P}_{1}$ state is $0.56 \mathrm{~ns}$ at atmospheric pressure, which is shorter than the excitation pulse duration of $\sim 6 \mathrm{~ns}$. As a consequence, the population in the $6^{3} \mathrm{P}_{1}$ essentially tracks the temporal profile of the excitation pulse, and accurate synchronization of the excitation pulses is critical. The use of a single pump laser is advantageous because it eliminates the "jitter" associated with the use of two pump lasers. In practice it was found that a slight delay between the two pulses produces optimal sequential excitation. Hence the two beams were spatially overlapped using dichroic optics, and a delay path ensured the $407.8 \mathrm{~nm}$ pulse arrived $2-3 \mathrm{~ns}$ after the $253.7 \mathrm{~nm}$ pulse. In addition, the $253.7 \mathrm{~nm}$ beam passed though a $6 \times$ beam expander to reduce the flux and produce better spatial overlap with the $407.8 \mathrm{~nm}$ beam. As noted above, typical pulse energies were $\sim 1 \mathrm{~mJ}$ at $253.7 \mathrm{~nm}$ and $5 \mathrm{~mJ}$ at $407.8 \mathrm{~nm}$, and the combined beams, after expansion of the $253.7 \mathrm{~nm}$ beam, were $\sim 5 \mathrm{~mm}$ in diameter. When sampling was performed in the trailer, the combined beams then passed through a sample cell and a reference cell and then terminated in a beam dump. The sample and reference cells were identical and constructed of 1 in. i.d. Pyrex. They were $12 \mathrm{in.}$ long with two $1 \mathrm{in}$. side arms attached at the midpoint. Oring joints (\#25) at the ends of both the main cell axis and the side arms allowed for windows to be attached and easily removed for cleaning or exchange. When the sample cell is utilized, air is pulled through a $1 / 4$ in. o.d. Teflon sampling line with an inlet located above the roof of the trailer. No filters are placed on the inlet. If the ambient temperature is significantly above the trailer temperature and the humidity is high, then the sample air is passed through a cold trap, set in an ice bath, to prevent condensation in the sampling lines inside the trailer. For open-air in situ sampling on the trailer roof, the beams pass through the reference cell and are directed by mirrors though a hole in the trailer roof. During RAMIX a single PMT was located on the trailer roof. For sampling with the second-generation system in Miami, two PMTs were located on the trailer roof. After exiting the roof the beam then passed $\sim 1 \mathrm{~cm}$ in front of the photocathode of the PMT or PMTs that were located $\sim 3 \mathrm{ft}$ above the trailer roof.

A slow flow $\left(\sim 100 \mathrm{cc} \mathrm{min}^{-1}\right)$ of zero-grade air passed over a permeation tube located in a temperature-controlled oven, (reference permeation oven in Fig. 2), and provided a stable flow of $\operatorname{Hg}(0)$ to the reference cell. The 2P-LIF signal from the sample cell was monitored by two solar-blind PMTs (Hammamatsu) on opposite sides of the sample cell, each aligned perpendicular to the axis of the excitation beams. The use of two PMTs allowed for the dynamic range of the detection system to be increased; increased the number of photons detected; and, as discussed below, allowed for us to distinguish between real fluctuations in $\operatorname{Hg}(0)$ concentration and random fluctuations associated with photon statistics. The 2P-LIF signal from the reference cell was monitored by a single PMT aligned perpendicular to the axis of 


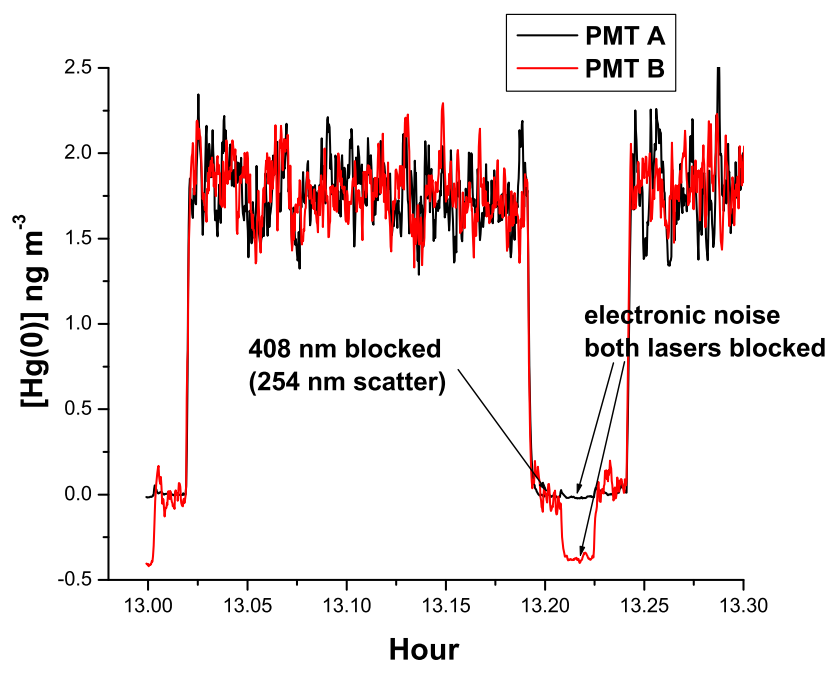

Figure 3. 2P-LIF signal from sample cell collected on 1 September, from the boxcar channels (effective averaging of 70 shots at $10 \mathrm{~Hz}$, i.e., $7 \mathrm{~s}$ ). Signals from both detection PMTs are shown. The $253.7 \mathrm{~nm}$ scattered light and the electronic background noise are labeled.

the excitation beams. The signal from all three PMTs was amplified and processed by boxcar integrators (Stanford Research Systems). Both the single-shot and 100-shot exponential average outputs of the boxcar units were digitized with 13 bit resolution and stored in a computer. The detection efficiency of the solar-blind PMTs drops off significantly for wavelengths longer than $200 \mathrm{~nm}$, so no filters were used to discriminate against background trailer light or laser scatter. Scattered laser light was monitored by taking background measurements in which both the 407.8 and $253.7 \mathrm{~nm}$ beams were blocked, giving electronic noise, and then monitoring scatter from both excitation beams separately. Neither PMT saw any scatter from the $407.8 \mathrm{~nm}$ excitation beam. A small amount of $253.7 \mathrm{~nm}$ scatter was observed, and so only the $253.7 \mathrm{~nm}$ scatter was routinely monitored. Figures 3 and 4 display 2P-LIF signals monitoring ambient air, as collected by the computer from the boxcar units; the data are a small section of the 1 and 2 September 2011 data discussed below. Figure 3 shows the boxcar-averaged output for both sample PMTs. The $\mathrm{Hg}(0)$ concentration is proportional to the $2 \mathrm{P}$ LIF signal detected when both the 253.7 and $407.8 \mathrm{~nm}$ beams are present minus the signal produced by the scattered light from the $253.7 \mathrm{~nm}$ laser beam, and the absolute concentration scale has been calibrated as discussed below. The electronic noise and $253.7 \mathrm{~nm}$ scatter are labeled in Fig. 3, and it can be seen that the sensitivity of the PMTs to $253.7 \mathrm{~nm}$ scatter is different, with tube B seeing significantly more scatter. This is due to the variability in the production of the PMTs. The voltage and hence the gain of the PMTs was adjusted to optimize the sensitivity and dynamic range of the 2P-LIF signal; however, tube B had higher gain and required more frequent adjustment. All data were processed to

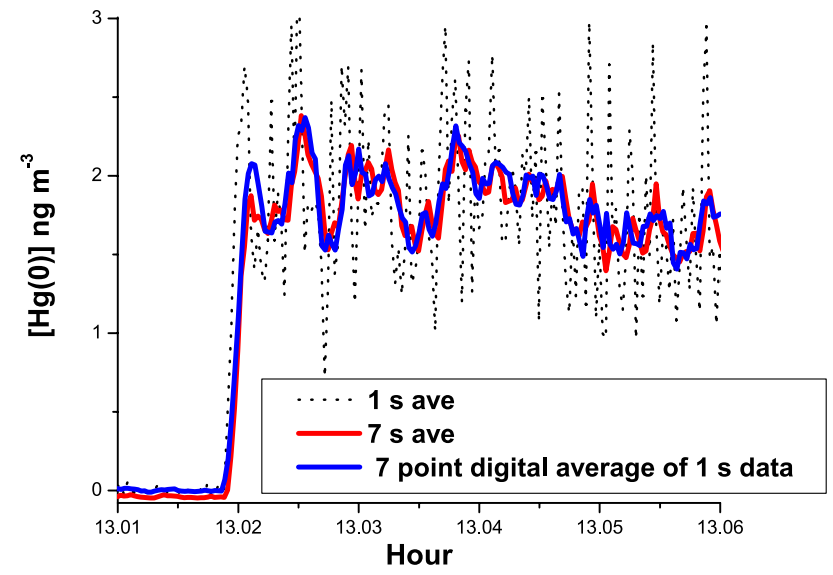

Figure 4. Comparison of $1 \mathrm{~s}$ average of $10 \mathrm{~Hz}$ data, output of boxcar averaged data, and a $7 \mathrm{~s}$ smoothing of the $1 \mathrm{~s}$ data.

account for the varying amplification of the PMTs and were then background-subtracted.

In Fig. 4 a $180 \mathrm{~s}$ slice of data shows the $1 \mathrm{~s}$ average of the $10 \mathrm{~Hz}$ single-shot data together with the exponentially averaged output of the boxcar and a $7 \mathrm{~s}$ smoothing of the single-shot data. The agreement between the digitally averaged single-shot data and the analogue boxcar average is excellent. It shows that a nominally 100 -shot exponential average is essentially equivalent to a $7 \mathrm{~s}$ smoothing of the singleshot data.

Either a Tekran 2537A or 2537B mercury analyzer was located downstream from the sample cell and sampled 2 standard liter per minute from the gas flow. The Tekran sampled through a $1 \mu$ Teflon particle filter, but no additional filters were used. A mass flow controller (MFC) and diaphragm pump located downstream from the Tekran pulled an additional $8 \mathrm{slpm}$ of air, and so the total flow through the sampling cell was $10 \mathrm{slpm}$. The sample cell was connected to the RAMIX manifold by $1 / 4 \mathrm{in}$. Teflon tubing. The manifold is described in detail by Finley et al. (2013). The sample air could be routed through a second, temperature-controlled, permeation oven ("calibration permeation oven" in Fig. 2) that contained a low-output permeation tube. The temperature was set to produce an addition of typically $5 \mathrm{ng} \mathrm{m}^{-3}$ of $\mathrm{Hg}(0)$ above ambient, as measured by the Tekran 2537. A constant $10 \mathrm{slpm}$ flow of zero-grade air passed through the calibration permeation oven, except when it was switched into the manifold sampling line for a standard addition to the sample flow. The continuous gas flow ensured oven stability and eliminated the buildup of mercury in the oven. We fabricated both permeation ovens and the permeation tubes. The actual sampling configurations evolved over the course of the campaign and the appropriate specific sampling configurations are described in the Results section.

The instrument has been deployed in Miami, Florida, and Reno, Nevada, and in both places the ambient temperature 


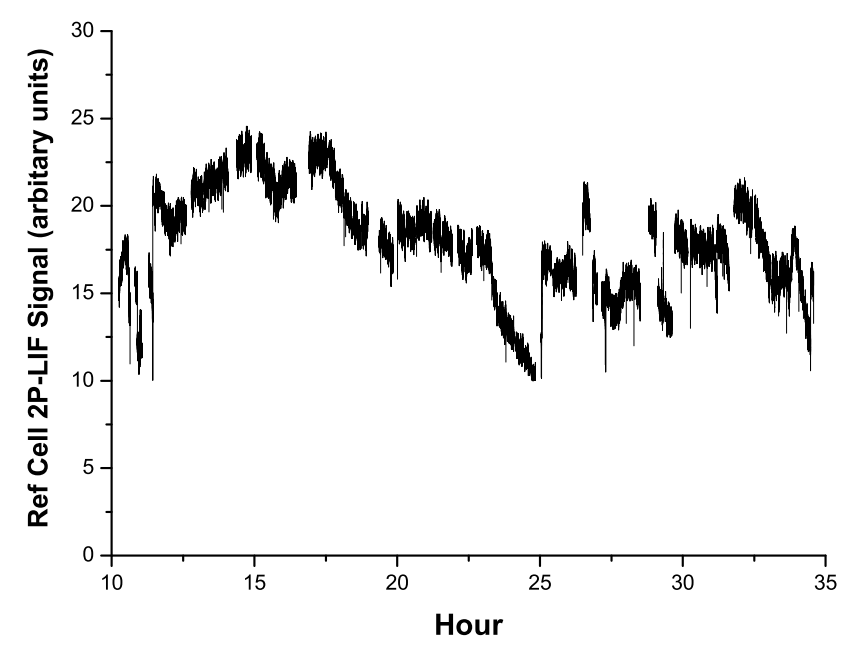

Figure 5. Reference cell signal over a $26 \mathrm{~h}$ sampling period on 1 and 2 September.

was well in excess of $30^{\circ} \mathrm{C}$ during the day. It was critical to keep the internal trailer temperature at a constant temperature close to $20^{\circ} \mathrm{C}$ to ensure stable operation of the laser systems; hence the trailer had three airconditioning units installed.

\subsection{Hg concentration units}

It has become standard practice in the mercury community to report $\mathrm{Hg}(0)$ concentrations in $\mathrm{ng} \mathrm{m}^{-3}$ referenced to 1 standard atmosphere and $0^{\circ} \mathrm{C}$ as these are the concentrations reported by the Tekran 2537 instruments, irrespective of the actual sampling pressure and temperature. As a consequence, these units, rather than being absolute concentrations, effectively report mixing ratios, and a knowledge of the sampling pressure and temperature is required to convert these "mixing ratios" to absolute concentrations. In this paper we will retain this convention using $\mathrm{ng} \mathrm{m}^{-3}$ referenced to 1 standard atmosphere and $0{ }^{\circ} \mathrm{C}$ unless clearly specified otherwise.

\subsection{Reference normalization}

At the start of a measurement cycle, the excitation dye lasers were optimized to produce the maximum 2P-LIF signal by maximizing output power and then tuning the wavelengths to generate the maximum 2P-LIF signal. At this point the laser wavelengths should be centered on the $\mathrm{Hg}(0)$ absorption features, and the 2P-LIF signal will be proportional to the $\mathrm{Hg}(0)$ concentration. In practice, both the wavelength and power of the excitation lasers can drift and the sensitivity of the 2P-LIF signal will change. Typically, after an initial startup period, we found the laser systems to be remarkably stable for several hours without requiring adjustment. Nevertheless the power will decrease as the laser dyes degrade and wavelengths can drift as a result of temperature variation and mechanical stability. This is a particular challenge in a mobile laboratory. At the excitation powers used in these experiments, the two atomic transitions are partially saturated and there is no simple relationship between the 2P-LIF signal and the laser powers. Small drifts in wavelength are also difficult to monitor and correct for. To compensate for these drifts, the 2P-LIF signal was monitored in a reference cell that maintained a constant concentration of $\mathrm{Hg}(0)$. Any drifts in power or wavelength were then observed as a change in the 2P-LIF signal from the reference cell. The 2P-LIF signal from the sample cell was then normalized to this reference signal. Figure 5 shows the 2P-LIF signal from the reference cell during $26 \mathrm{~h}$ of continuous measurement on 1 and 2 September. The reference 2P-LIF signal, which should be constant if the lasers showed no drift, shows fluctuations of $20 \%$ over the first $15 \mathrm{~h}$ and then a precipitous drop in power as the dyes degrade. At hour 25, 01:00 on 2 September, the dyes were changed and the power restored. The reference cell signal also provides a long-term monitor of the performance of the laser and detection systems. In this work, all of the data from ambient samples were background-corrected and then normalized to the reference cell.

We found that changes in crystal alignment and wavelength shifts reducing the 2P-LIF signal by a factor of 5 were corrected by normalizing to the reference cell. However, we have not performed a systematic investigation of the relative responses of the sample and reference systems to changes in power and wavelength drift; we plan to do this as part of any future deployment.

\subsection{Calibration}

Laser-induced fluorescence is a relative technique since it is not possible to accurately relate the fluorescence signal measured by the PMT to the absolute concentration of the species being monitored. As a consequence, it must be independently calibrated by standard addition of a calibration gas or by comparison with another absolute technique. The $2 \mathrm{P}$ LIF system was calibrated by reference to the Tekran 2537 that was sampling simultaneously from the gas flow. Typically the integrated 2P-LIF signal was referenced to 10 or 15 min of Tekran sampling during each measurement period, and the response of both instruments was compared over the whole measurement period. The Tekran 2537 utilizes a built-in, gravimetrically calibrated $\mathrm{Hg}(0)$ permeation tube to calibrate the CVAFS fluorescence signal. Ambient concentrations and spikes were being simultaneously monitored by several Tekran 2537 units; these experiments will be described in detail elsewhere. Furthermore, standard addition of $\operatorname{Hg}(0)$ to the sample flow could be introduced by rerouting the sample flow through the calibration permeation oven. We were unable to obtain a gravimetrically calibrated $\mathrm{Hg}(0)$ permeation tube prior to RAMIX and, as a result, the standard addition procedure did not offer an independent calibration. However the Tekran and 2P-LIF responses were compared as described below. For future instrument deployments we will utilize a low-output, gravimetrically calibrated 
permeation tube to offer an independent absolute calibration of the $\mathrm{Hg}(0)$ concentration that will offer an additional check on the Tekran response.

\subsection{Instrument response and linearity}

The instrument response and linearity of an LIF sensor are dependent on quenching or absorption of the fluorescence signal by atmospheric gases. The $\mathrm{Hg} 6^{3} \mathrm{P}_{1}$ state that is excited in the first step of the $2 \mathrm{P}$-LIF scheme is quenched very efficiently by $\mathrm{O}_{2}$, but data are limited on the quenching efficiency of the higher electronic states that are subsequently excited prior to fluorescence. Nevertheless it is reasonable, based on $6^{3} \mathrm{P}_{1}$ quenching rates, to conclude that $2 \mathrm{P}$-LIF fluorescence efficiency is low at atmospheric pressure. In addition, the $184.9 \mathrm{~nm}$ fluorescence signal is absorbed by both $\mathrm{O}_{2}$ and $\mathrm{H}_{2} \mathrm{O}$. The absorption cross sections of $\mathrm{O}_{2}$ and $\mathrm{H}_{2} \mathrm{O}$ are $\sim 1 \times 10^{-20}$ and $7 \times 10^{-20} \mathrm{~cm}^{2}$ molecule ${ }^{-1}$, respectively (Creasey et al., 2000). The path length from the 2P-LIF beams to the PMT photocathode is $\sim 3 \mathrm{~cm}$, which means that the $184.9 \mathrm{~nm}$ bean is attenuated by $\sim 15 \%$ by $\mathrm{O}_{2}$ at atmospheric pressure and by $0.7 \%$ per Torr of $\mathrm{H}_{2} \mathrm{O}$. If both the pressure and gas composition are constant, then both the fluorescence efficiency and the attenuation of the 2P-LIF are constant and the 2P-LIF signal should be proportional to the $\mathrm{Hg}(0)$ concentration. If gas composition or pressure are changing significantly, this could produce deviations from linearity. This is a significant issue in the use of 2P-LIF in reactive flows such as combustion or plasma environments, and it could be significant in an aircraft deployment. For groundbased measurements the pressure is constant, and the only potential issue is a change in the $\mathrm{H}_{2} \mathrm{O}$ partial pressure. We performed linearity calibrations employing the mobile laser system and using standard addition of $\operatorname{Hg}(0)$ to air. We also estimated the effective fluorescence efficiency in our experimental configuration by measuring the relative fluorescence yields in air and $\mathrm{He}$, and we examined the effects of changes in $\mathrm{H}_{2} \mathrm{O}$ concentration on the 2P-LIF fluorescence response.

\subsubsection{P-LIF linearity in air}

These experiments used an experimental configuration that was identical to that used during the RAMIX intercomparison to compare the 2P-LIF signal with $\mathrm{Hg}(0)$ concentrations measured by the Tekran 2537B. A constant flow of zerograde air passed through a temperature-controlled aluminum oven containing a Teflon mercury permeation tube, supplying a constant amount of $\operatorname{Hg}(0)$ into the air stream. The flow was controlled by an MFC. An additional flow of air, controlled by a separate MFC, bypassed the permeation tube and was then added to the permeation oven flow in a mixing line to dilute the $\operatorname{Hg}(0)$ concentration and provide variable concentrations for study. Another MFC, backed by a mechanical pump, downstream of the 2P-LIF sample cell, ensured a constant 5.0 slpm flow through the LIF sample cell (including air

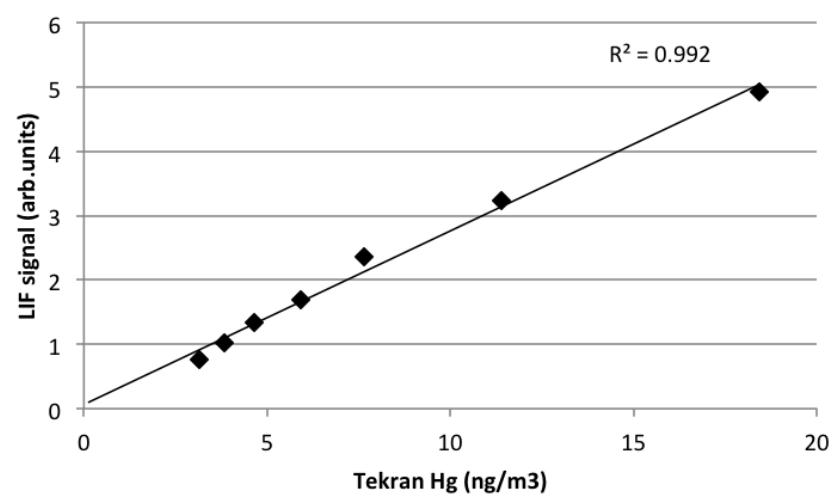

Figure 6. The 2P-LIF signal as a function of $\mathrm{Hg}(0)$ concentration measured with the Tekran instrument in zero-grade air together with a calculated regression line.

flow sampled by the Tekran), while a vent line open to ambient atmosphere upstream of the sample cell kept the entire sampling system at atmospheric pressure. The simultaneous detection of $\mathrm{Hg}(0)$ using $2 \mathrm{P}$-LIF and Tekran measurements was conducted over a range of $3-18.5 \mathrm{ng} \mathrm{m}^{-3}$ by varying the air flow through the dilution line. There is an excellent correlation between the 2P-LIF signal and the Tekran measurements, as shown in Fig. 6 with a least-squares linear regression of the data giving an $R^{2}$ of 0.996 and an intercept of $0.06 \pm 0.1$, i.e., zero within the precision of the measurement. The experiment was then repeated with higher $\mathrm{Hg}(0)$ concentrations $\left(12.5-30 \mathrm{ngm}^{-3}\right)$, and again there was an excellent linear correlation between the 2P-LIF signal and the Tekran measurements: $R^{2}=0.998$ and a zero intercept at a $2 \sigma$ level of precision. In both cases the variations in concentration were in excellent agreement with those calculated based on the measured dilution. These results verify our prior work in $\mathrm{N}_{2}$ using the "field instrument" configuration and confirm that, as expected, at constant pressure the 2P-LIF signal varies linearly with $\mathrm{Hg}(0)$ concentration in air.

The relative fluorescence efficiencies in air and $\mathrm{He}$ were measured by passing both gases through the permeation oven that was used for standard addition of $\mathrm{Hg}(0)$ to sample gases. In this case, zero-grade air or He was used, and the 2P-LIF signal was monitored in each case. The average of these experiments gave a $2 \mathrm{P}-\mathrm{LIF}$ signal in air that was $3 \%$ of the signal in He. Approximately $15 \%$ of the reduction in signal is due to direct absorption of the 2P-LIF signal by $\mathrm{O}_{2}$, and the remaining reduction is probably due to enhanced quenching by $\mathrm{O}_{2}$. Assuming the maximum possible $100 \%$ in $\mathrm{He}$ as an example, we would obtain a fluorescence efficiency of approximately $3.5 \%$ in air. As noted above in the low laser power linear fluorescence regime, we would expect a fluorescence efficiency of less than $0.5 \%$ based on quenching of the $6^{3} \mathrm{P}_{1}$ state; additional quenching of the $7^{1} \mathrm{~S}_{0}$ and $6^{1} \mathrm{P}_{1}$ states would reduce the fluorescence efficiency even more. 


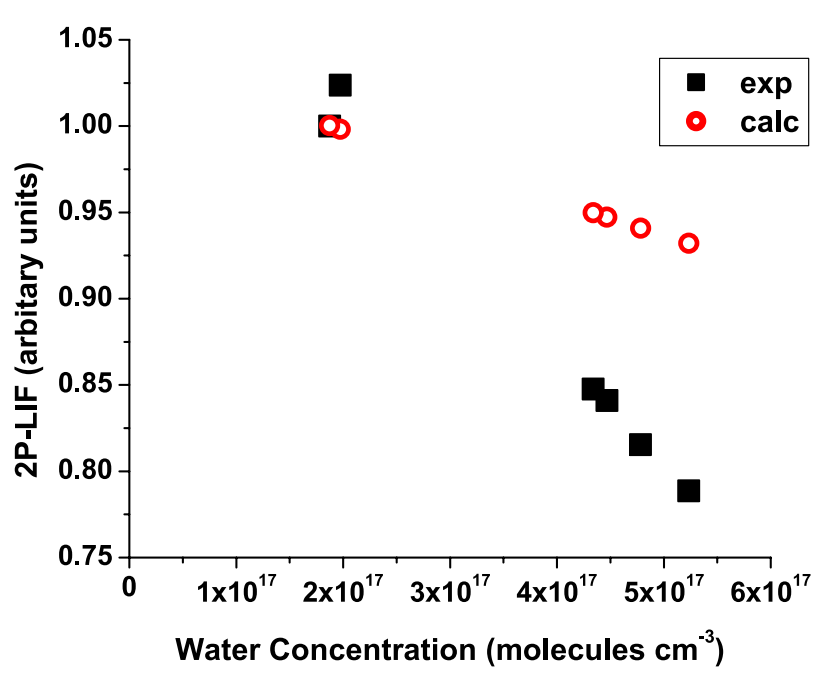

Figure 7. The 2P-LIF signal as a function of $\mathrm{H}_{2} \mathrm{O}$ concentration. The calculated points show the expected attenuation based only on absorption of the 2P-LIF signal by $\mathrm{H}_{2} \mathrm{O}$.

While the fluorescence efficiency in He is probably less than $100 \%$, it is expected to be high. As shown previously, both excitation transitions are partially saturated at the typical powers and laser fluxes used here, and this is likely to explain the higher fluorescence efficiency.

The impact of water vapor was measured by pulling outside air through a water bubbler and measuring the 2P-LIF signal as a function of humidity. Relative humidity was monitored using a humidity sensor and the absolute concentration of water was calculated using the trailer temperature. Figure 7 shows the 2P-LIF signal as a function of water concentration, and it can be seen that the signal drops as the concentration increases. As noted above we expect a decrease in the 2P-LIF signal as a result of absorption by the water vapor, but the observed decrease, shown in Fig. 7 as the "exp" line, is larger than calculated due to absorption alone. There are no literature data on the quenching of excited states of $\mathrm{Hg}(0)$ by water, but this result suggests it is also an extremely efficient quencher; this requires further investigation. Typically, the $\mathrm{H}_{2} \mathrm{O}$ partial pressure is constant over extended periods of time and the diurnal change in relative humidity is a consequence of temperature change. Nevertheless, we plan to incorporate a humidity measurement downstream of the Tekran and routinely monitor the $\mathrm{H}_{2} \mathrm{O}$ partial pressure. We also plan to measure the change in the 2P-LIF signal as a function of the $\mathrm{H}_{2} \mathrm{O}$ partial pressure in one atmosphere of air.

\section{Interference effects}

As we noted above, the 2P-LIF excitation schemes, involving sequential excitation of two atomic transitions followed by detection of the emission from a third, are extremely spe- cific and preclude detection of anything other than atomic mercury. However, it is possible to conceive of interferences, i.e., spurious effects that produce a $2 \mathrm{P}-\mathrm{LIF} \operatorname{Hg}(0)$ signal that does not come from ambient $\mathrm{Hg}(0)$. Examples of such interferences include photochemistry coupled with chemistry, the classic example in atmospheric chemistry being the $\mathrm{O}^{1} \mathrm{D}$ interference in monitoring ambient $\mathrm{OH}$ (Heard and Pilling, 2003). In this case, excitation of $\mathrm{OH}$ on the A-X (1-0) band photodissociates $\mathrm{O}_{3}$, generating $\mathrm{O}^{1} \mathrm{D}$ that reacts with water vapor generating $\mathrm{OH}$. Because of the concentration of water vapor in the lower atmosphere and the very fast rate coefficient for this reaction, a single $282 \mathrm{~nm}$ laser pulse can generate $\mathrm{O}^{1} \mathrm{D}$ and detect the $\mathrm{OH}$ product, and this essentially precludes this approach to monitoring tropospheric $\mathrm{OH}$. In the 2P-LIF detection approach the $253.7 \mathrm{~nm}$ laser will dissociate ozone, and while most of the $\mathrm{O}^{1} \mathrm{D}$ produced will be collisionally relaxed to $\mathrm{O}^{3} \mathrm{P}$ followed by recombination to reform $\mathrm{O}_{3}$, a small fraction will react with water to form $\mathrm{OH}$. The reaction of $\mathrm{Hg}(0)$ with $\mathrm{OH}$ is very slow, and this will not have any impact on the 2P-LIF measurements (Bauer et al., 2003).

The second type of interference is purely photochemical in which the probe laser photodissociates a parent molecule, producing, as a photofragment, the molecule or atom under study. An example of such an interference appeared in early attempts to monitor $\mathrm{H}$ atoms in flames using two-photon excitation at $205 \mathrm{~nm}$ (Goldsmith, 1986). It became clear that the two-photon LIF signal did not reflect the nascent $\mathrm{H}$ atom concentrations in the flames but was in fact produced by the photodissociation of water vapor. Photolysis of oxidized mercury compounds such as $\mathrm{HgCl}_{2}$ and $\mathrm{HgBr}_{2}$ can produce some $\operatorname{Hg}(0)$ photofragments; however the absorption cross section for $\operatorname{Hg}(0)$ is approximately 3 orders of magnitude greater than that of $\mathrm{HgX}_{2}$ compounds at $253.7 \mathrm{~nm}$ and under ambient conditions the concentration of $\mathrm{HgX}_{2}$ is normally much lower than $\mathrm{Hg}(0)$ (Templet et al., 1972; Maya, 1977). We will discuss the interference tests conducted during RAMIX campaign elsewhere, but it should be noted that there are no potential effects in monitoring ambient $\mathrm{Hg}(0)$. This is not necessarily the case in reacting combustion flows; in an environment in which most of the mercury is present as $\mathrm{Hg}(\mathrm{II})$, the photochemical interference could become significant. 


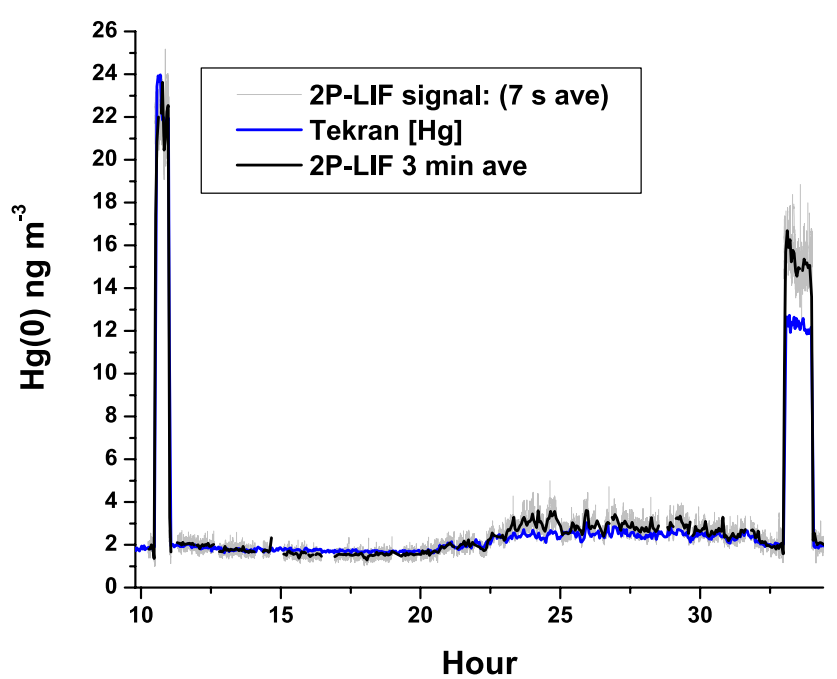

Figure 8. 2P-LIF and Tekran signals over a $26 \mathrm{~h}$ sampling period on 1 and 2 September. The Tekran samples every $2.5 \mathrm{~min}$. The $7 \mathrm{~s}$ boxcar output is shown together with a 3 min smoothing of the boxcar output.

\section{Results}

\subsection{General overview}

For the RAMIX intercomparison the mobile lab was towed from Miami to Reno, a 3000-mile journey, in August 2011. After arrival in Reno it took approximately 3 days to hook up utilities, set up the lab and begin taking data. For most of the intercomparison we sampled from the RAMIX manifold, which was designed to allow for simultaneous sampling by the four RAMIX participants and also by the University of Nevada, Reno (UNR), host group. The manifold is described in detail by Finley et al. (2013). During the RAMIX campaign we sampled on 18 days, typically sampling for between 4 and $6 \mathrm{~h}$. The longest period of continuous sampling lasted for $26 \mathrm{~h}$ and occurred on 1 and 2 September. Over this 18-day period we sampled from the RAMIX manifold, and, in addition, at the end of the campaign we sampled ambient air independently and also attempted to measure RGM by pyrolyzing the sample air and measuring the difference between $\mathrm{Hg}(0)$ and TGM. During this period the ambient air sampled by the RAMIX manifold was spiked with additional known concentrations of $\mathrm{Hg}(0), \mathrm{RGM}(\mathrm{HgBr} 2), \mathrm{H}_{2} \mathrm{O}$, and $\mathrm{O}_{3}$ both separately and concurrently. The RAMIX results, including a detailed comparison with multiple Tekran instruments, the interference tests and the preliminary attempts to measure RGM, will be described elsewhere. Here we focus on the overall instrument performance, derived limits of detection and, in addition, the preliminary results from $10 \mathrm{~Hz}$ and $50 \mathrm{~Hz}$ systems utilizing the $313.2 \mathrm{~nm}, 6^{3} \mathrm{D}_{1}-6^{3} \mathrm{P}_{1}$ transition for the second excitation photon.

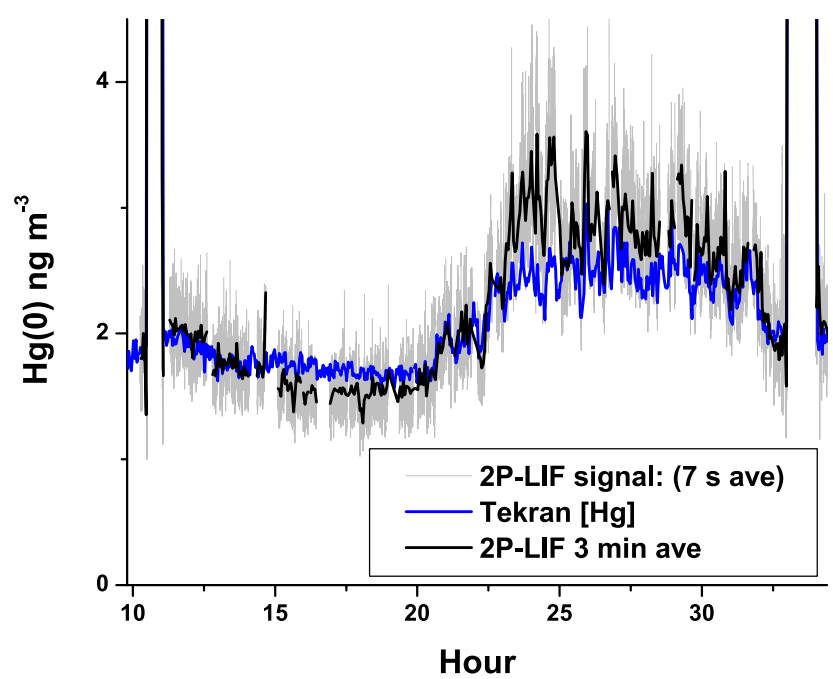

Figure 9. LIF and Tekran signals over a $26 \mathrm{~h}$ sampling period on 1 and 2 September. The Tekran samples every $2.5 \mathrm{~min}$. The $7 \mathrm{~s}$ boxcar output is shown together with a 3 min smoothing of the boxcar output. The concentration scale is expanded to show the ambient data more clearly.

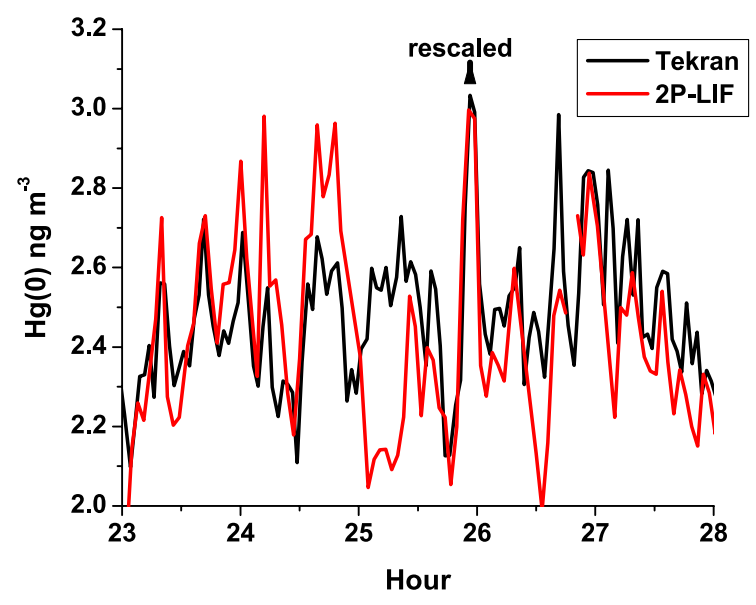

Figure 10. An expanded section of the 1-2 September sampling period showing the nighttime variation in $\mathrm{Hg}(0)$ concentration detected by the Tekran and 2P-LIF instruments. The 2P-LIF data are rescaled to the labeled peak.

\subsection{Extended sampling}

The quality of the data during an extended operation can be gauged from data obtained on 1 and 2 September, when we were able to perform $26 \mathrm{~h}$ of continuous sampling. Figures 8 and 9 show the full sampling period, which began shortly before 10:00 on 1 September. The $x$ axis shows the hour after midnight on 31 August in local time in Reno, and the $y$ axis shows the measured concentrations in $\mathrm{ng} \mathrm{m}^{-3}$ as measured by the Tekran 2537B. Since the 2P-LIF measurement gives a relative response, it is necessary to calibrate the $2 \mathrm{P}$-LIF signal using the Tekran. The data prior to hour 11, including the 


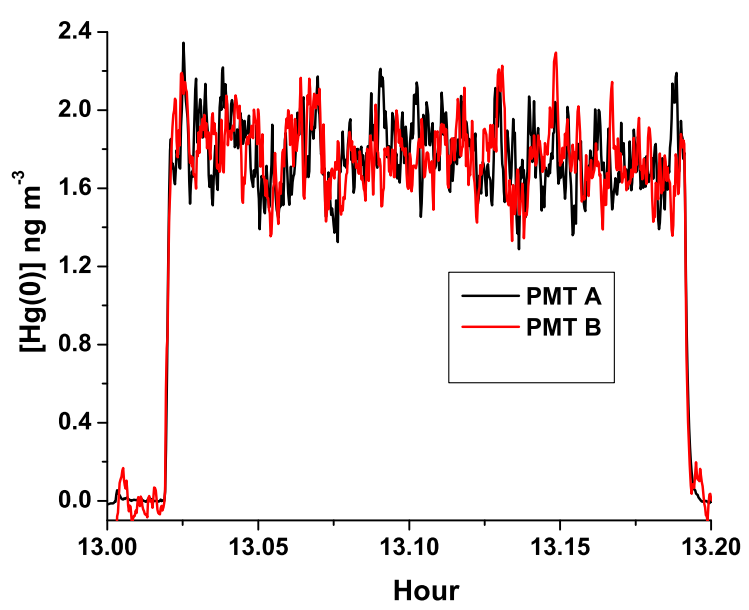

Figure 11. 2P-LIF signals from the two individual boxcar channels over a 10 min sampling period at $\sim$ 13:00 local time on 1 September.

initial large manifold spike of $\operatorname{Hg}(0)$ at $\sim$ hour 10.5, were calibrated relative to $10 \mathrm{~min}$ of ambient Tekran sampling at hour 10.2. At hour 11 the $253.7 \mathrm{~nm}$ turning mirror was bumped; therefore a realignment of the beams was required. Hence, for the remaining $25 \mathrm{~h}$ of sampling, the $2 \mathrm{P}$-LIF signal was calibrated relative to $10 \mathrm{~min}$ of ambient Tekran measurements at hour 13.1, shortly after 13:00 on 1 September. The Tekran signal is a $2.5 \mathrm{~min}$ average; the $2 \mathrm{P}$-LIF signals are the average of the boxcar outputs, effectively a $7 \mathrm{~s}$ average of $10 \mathrm{~Hz}$ data and a 3 min smoothing of that data, which makes it easier to track the differences between the Tekran and 2PLIF signals. The 2P-LIF signals from each PMT have been corrected for laser background as well as changes in gain when PMT voltages were adjusted and then normalized to changes in the reference cell signal. The average of these two background-corrected signals was then taken. Figure 9 shows the full sampling record for the $26 \mathrm{~h}$ sampling period but with an expanded concentration scale. We began taking data shortly before 10:00 and saw the 10:00 elemental mercury spike that was added to the RAMIX manifold. At hour 33, corresponding to 09:00 on 2 September, we also saw the manifold spike, and shortly after that we stopped sampling from the manifold. The expanded concentration scale in Fig. 9 shows the ambient air signal more clearly, and we see a diurnal variation in the $\operatorname{Hg}(0)$ concentration that is captured in both the 2P-LIF and Tekran data. Figures 8 and 9 show that there are issues in the scaling of the signals and that the 2P-LIF and Tekran signals are not responding in an absolutely linear fashion with respect to each other. We had significant problems with the response and calibration of the Tekran 2537B, which we suspect are due to the large drop in pressure between the manifold and sampling cell. For this data set we find that calibrating the 2P-LIF signal using the UNR Tekran data at the second spike produces better agreement over the $26 \mathrm{~h}$ sampling period. In the figures the gaps in the 2P-LIF signal typically correspond to 3 min gaps when

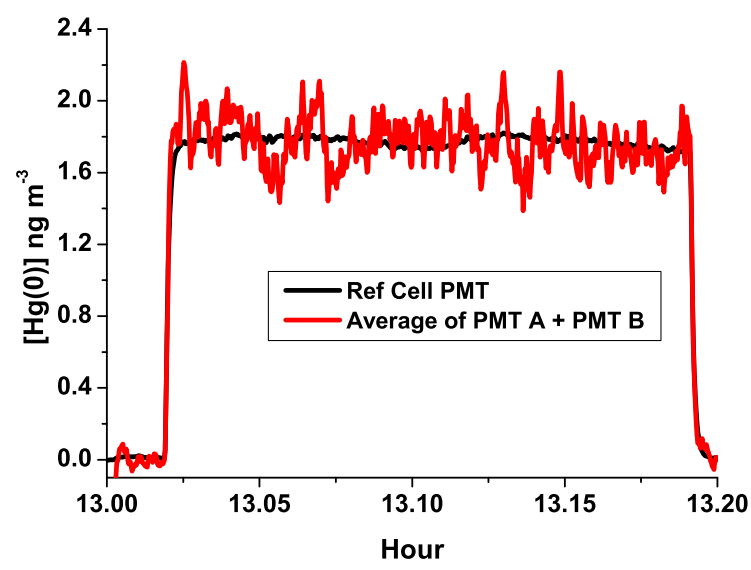

Figure 12. Average of the 2P-LIF shown in Fig. 11 together with the reference cell signal normalized to the same amplitude.

laser background signals were recorded. In these plots, these periods were set equal to zero. If we examine a $5 \mathrm{~h}$ period during the night, we see significant fluctuations that are captured by both the 2P-LIF and Tekran instruments; however the concentration scaling is an issue. Figure 10 shows the $2 \mathrm{P}$ LIF data rescaled to the Tekran concentration at a concentration peak that occurs shortly before hour 26.2 on 2 September; we see reasonable but certainly not perfect agreement in the fluctuations in $\operatorname{Hg}(0)$ concentration. As noted above, we see better agreement over the $26 \mathrm{~h}$ sampling period if we normalize to the UNR Tekran. On 5 September the 2P-LIF instrument sampled for $7 \mathrm{~h}$, and on this day there was excellent agreement between three independently operated Tekran instruments and the normalized 2P-LIF signal, including two large manifold $\operatorname{Hg}(0)$ spikes. We will address the issues of variability between the Tekran and 2P-LIF instruments elsewhere. Nevertheless, we conclude that both instruments are clearly measuring $\operatorname{Hg}(0)$.

The 2P-LIF instrument shows short-term temporal variations in $\mathrm{Hg}(0)$ concentration and it is important to determine how much of the variation reflects actual changes in the $\mathrm{Hg}(0)$ concentration in the atmosphere as opposed to statistical noise in the 2P-LIF signal. This is important in evaluating the RAMIX data set and critical in evaluating the feasibility of eddy correlation measurements with this system. Ideally we could assume that, after laser-related fluctuations are corrected with the reference signal, features that are correlated between the two PMTs reflect a real variation in the $\mathrm{Hg}(0)$ concentration. However the difference in the susceptibility of the two PMTs to the $253.7 \mathrm{~nm}$ scatter makes this somewhat problematic. Figure 11 shows a greatly expanded timescale capturing 10 min of continuous sampling at hour 13. This is the section of the data set that was used to calibrate the 2P-LIF signals for the period from hour 11 to 36 by normalizing the integral of the $10 \mathrm{~min} 2 \mathrm{P}$-LIF signals to the Tekran concentration. The figure shows the two individual boxcar outputs, i.e., $7 \mathrm{~s}$ averages of the $10 \mathrm{~Hz}$ sig- 


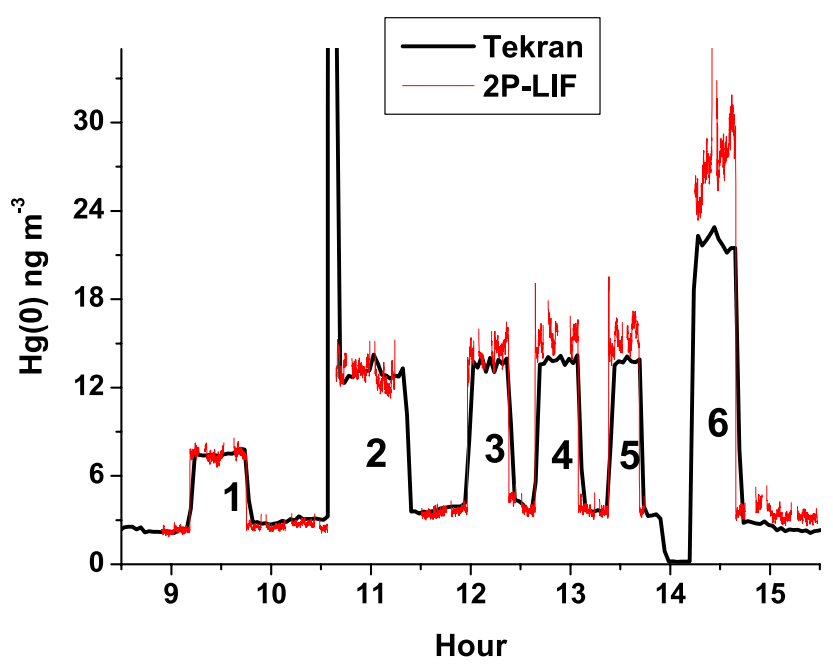

Figure 13. Data from 8 September showing ambient concentration, manifold spikes $(1,6)$, and in situ 2P-LIF calibration using permeation oven additions $(2,3,4,5)$.

nals. Figure 12 shows the average of the two signals and the reference cell output normalized to the same amplitude as PMTs A and B. It is apparent that there are fluctuations on a $7 \mathrm{~s}$ timescale that are captured by both 2P-LIF PMTs, but some of the fluctuations are not correlated. The comparison with the reference cell output shown in Fig. 12 demonstrates that the variation in the ambient 2P-LIF signal is not due to pulse-to-pulse or short-term wavelength variations in the probe lasers. There is almost no variation in the reference cell 2P-LIF signal during this period. In fact, the mean of the normalized signals is $1.7 \mathrm{ng} \mathrm{m}^{-3}$ and the $1 \sigma$ variation in the signals is $0.18,0.17$ and $0.03 \mathrm{ng} \mathrm{m}^{-3}$ for PMT A, PMT $\mathrm{B}$ and the reference PMT, respectively. In contrast, the $1 \sigma$ variation in the $253.7 \mathrm{~nm}$ scatter is $0.012 \mathrm{ng} \mathrm{m}^{-3}$ for PMT A and $0.071 \mathrm{ng} \mathrm{m}^{-3}$ for PMT B. Based on this we might conclude that the fluctuations we see in the PMT A signal are real; however we know that the quantum efficiencies of the solar-blind PMTs are very low, $\sim 0.1 \%$, and so we do not detect many photons per shot. The shot noise associated with sampling 70 laser pulses would be $\sim 12 \%$ detecting 1 photon per pulse and $\sim 2 \%$ detecting 25 photons per pulse. This is the $1 \sigma$ deviation in the magnitude of the signal that is assumed to be proportional to the number of photons detected. Hence it seems reasonable that at least some of the uncorrelated variations in the ambient $\mathrm{Hg}(0)$ signals from PMTs A and $\mathrm{B}$ are likely to be a result of photon statistics.

\subsection{Permeation oven calibrations}

Figure 13 shows data from 8 September, when we attempted an in situ calibration using permeation oven additions. On this day there were additional manifold spikes of $\operatorname{Hg}(0)$ at $\sim 9$ and $14 \mathrm{~h}$ and also ongoing manifold spikes of water and $\mathrm{HgBr}_{2}$. In Fig. 13 the manifold spikes are labeled as 1 and 6,

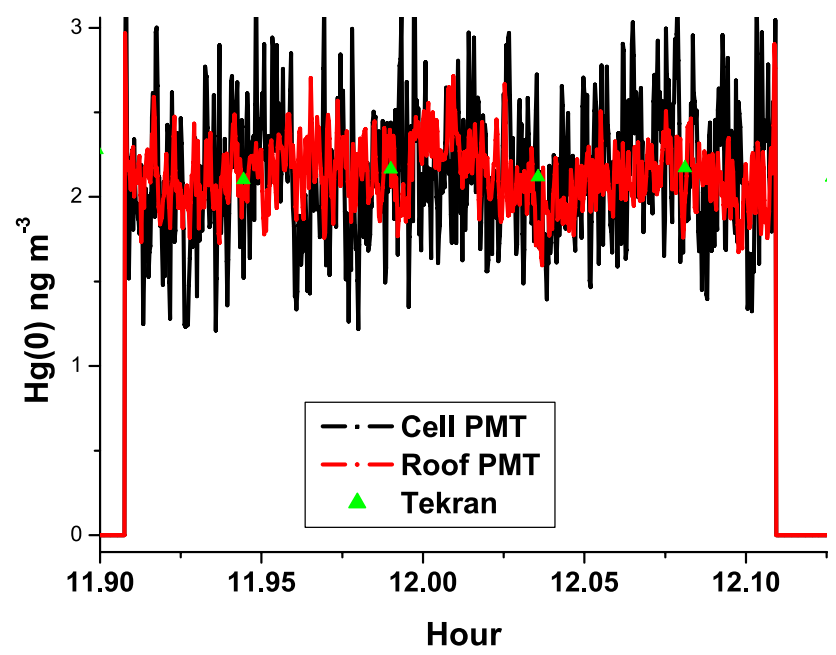

Figure 14. Comparison of 2P-LIF signals from PMTs located on the trailer roof and the sample cell. The signals are normalized to the concentrations measured by the Tekran. Data from 16 September at approximately noon.

and the agreement between the values reported by the UM, UW and UNR Tekrans was good. The inline $\mathrm{Hg}(0)$ additions are labeled as 2, 3, 4 and 5. The figure shows a comparison of the 2P-LIF and Tekran data with the 2P-LIF signal calibrated to manifold addition 1 at $\sim$ 09:00 It can be seen that, over the course of the $6 \mathrm{~h}$ of sampling, the 2P-LIF signal is drifting upward relative to the Tekran output. The integrated additions from the Tekran give an average addition of $9.7 \mathrm{ng} \mathrm{m}^{-3}$ for peak 2 , rising to $10.3 \mathrm{ng} \mathrm{m}^{-3}$ for peak 5 , and the concentrations for peaks 1 and 6 agree well with the other independent Tekran measurements. This suggests that the oven is not completely stable, with an output that rises by $\sim 6 \%$ over 3 , h. It also implies that the discrepancy between the measurements is a result of problems with the 2P-LIF response. A closer examination of the $2 \mathrm{P}$-LIF signal shows that the upward divergence is a result of the normalization procedure, i.e., a significant drop in the reference cell signal. We also found that there is some drift in the individual channels, i.e., the individual PMT outputs. This could be a result of problems with one or both of the PMTs or the cell windows but is more likely due to drifts in the signal processing electronics; this needs to be examined in more detail.

\subsection{Trailer rooftop sampling at RAMIX}

On the final day of the RAMIX experiment we sampled directly on the trailer roof, placing a PMT approximately $3 \mathrm{ft}$ above the trailer roof. The laser beams were directed through the sampling and reference cells within the trailer and were reflected vertically, passing through a hole in the trailer roof. The sample cell in the trailer was switched between a sample line located on the roof next to the roof PMT and the RAMIX manifold. This enabled us to perform direct, in situ 2P-LIF 


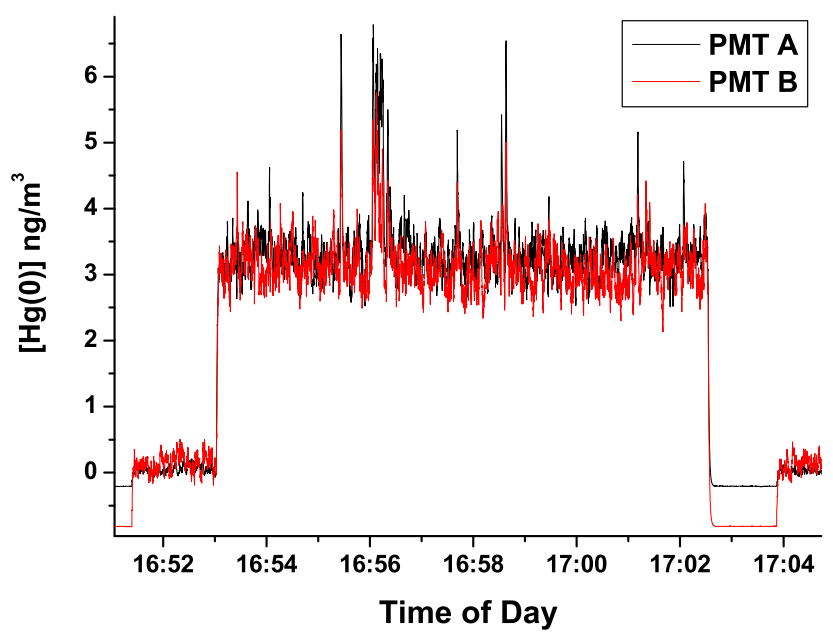

Figure 15. 2P-LIF signal from two individual boxcar channels with $253.7 \mathrm{~nm} / 313.2 \mathrm{~nm}$ excitation scheme using a $10 \mathrm{~Hz}$ laser system. The figure shows a $10 \mathrm{~min}$ slice of a $1 \mathrm{~h}$ sample.

measurements of the air above the trailer while simultaneously using a sampling line to pull air into the sample cell for 2P-LIF measurements inside the trailer. It is worth noting that the PMTs require no type of optical filter; hence the roof PMT had the excitation laser beams passing directly in front of the bare photocathode that was directly exposed to both laser scatter and sunlight.

The PMT on the sample cell was approximately $5 \mathrm{~cm}$ from the excitation lasers, constrained by the length of the sample cell side arms. Since the number of photons collected varies inversely as the square of the distance of the photocathode from the excitation beams, there is a significant advantage in working in ambient air with no sample cell. Firstly, there is an increase in signal because the PMT is closer to the excitation beam. Secondly, there is no $253.7 \mathrm{~nm}$ scatter from the cell windows. Figure 14 shows a comparison of the $2 \mathrm{P}$-LIF signals from the PMTs on the roof and in the sample cell. The signals are calibrated by the $\mathrm{Hg}(0)$ concentration measured by the Tekran after the sample cell. The fluctuations in the 2P-LIF signal from roof PMT are significantly smaller than the fluctuations in the cell PMT. This is consistent with the conclusion that these fluctuations are related to the limited number of photons collected.

\subsection{P-LIF using excitation of the $6^{3} \mathrm{D}_{1}-6^{3} \mathrm{P}_{1}$ transition}

In an effort to increase the fluorescence photon flux, we have investigated an alternate excitation scheme in which we pump the $6^{3} \mathrm{D}_{1}-6^{3} \mathrm{P}_{1}$ transition at $313.2 \mathrm{~nm}$ as the second step in sequential excitation. The $6^{3} \mathrm{D}_{1}$ level then fluoresces via the $6^{3} \mathrm{D}_{1}-6_{1} \mathrm{P}_{1}$ transition at $578.9 \mathrm{~nm}$, populating the $6^{1} \mathrm{P}_{1}$ level. As before, we monitor fluorescence from the $6^{1} \mathrm{P}_{1}-6^{1} \mathrm{~S}_{0}$ transition at $184.9 \mathrm{~nm}$. The experiment is similar to that described previously; however we now use the resid-

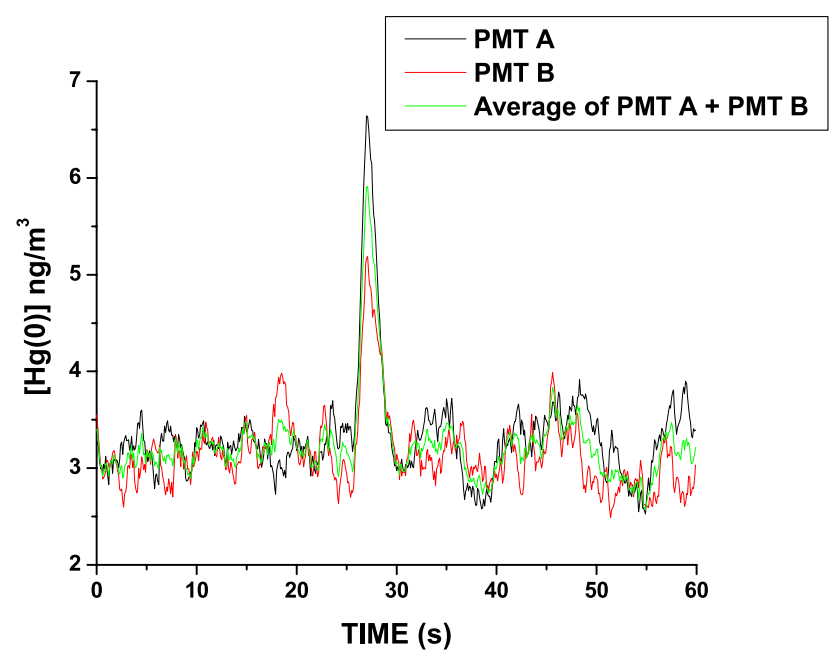

Figure 16. 2P-LIF signal with $253.7 \mathrm{~nm} / 313.2 \mathrm{~nm}$ excitation scheme showing data from Fig. 15 on an expanded scale, specifically the feature at hour 16.55. A 1 min section of data is shown; the scale is in seconds. The individual boxcar channels and their average are shown.

ual second harmonic of the Nd:YAG laser to pump a dye laser operating with DCM dye $\sim 626.4 \mathrm{~nm}$. The $626.4 \mathrm{~nm}$ is then frequency-doubled in a KPD crystal, producing the $313.2 \mathrm{~nm}$ excitation photon. This scheme allows us for to use the additional residual power at $532 \mathrm{~nm}$ that is not utilized in the first excitation configuration, but it requires the second dye laser to be frequency-doubled. Fig. 15 shows an example of data collected on the Rosenstiel School (RSMAS) campus with the trailer located next to the campus dock. The PMTs are located on the trailer roof, so no sampling cell is used. The air close to the PMTs was sampled using the Tekran to put the 2P-LIF signals on an absolute concentration scale. The data were obtained using the $10 \mathrm{~Hz} \mathrm{Nd:YAG} \mathrm{laser} \mathrm{to} \mathrm{pump}$ the dye lasers. Figure 16 has an expanded $x$ axis showing a 1 min segment of the data and includes the individual PMT outputs and their average with the time axis in seconds. It can again be seen that an examination of the correlation between the 2P-LIF signals from two PMTs is useful for seeing the difference between real fluctuations in the $\operatorname{Hg}(0)$ concentration and noise from photon statistics. For example, it is clear that the feature at 16:55:26 showing an $\sim 3 \mathrm{ng} \mathrm{m}^{-3}$ spike in the $\operatorname{Hg}(0)$ concentration is real. This feature has a width at half maximum of $\sim 3 \mathrm{~s}$ and again demonstrates the ability of the instrument to capture a very rapid fluctuations in $\mathrm{Hg}(0)$ concentration at ambient levels. We never saw this type of fluctuation during RAMIX, and these observations, with a location close to the RSMAS dock overlooking Biscayne Bay, are interesting.

Figure 17 gives an example of the current performance of the $50 \mathrm{~Hz}$ system, taking 5-shot averages to give an effective sampling rate of $10 \mathrm{~Hz}$. 
Table 1. Typical detection sensitivities.

\begin{tabular}{lrrrrr}
\hline $\begin{array}{l}\lambda_{2} \\
\mathrm{~nm}\end{array}$ & $\begin{array}{r}\lambda_{254} \text { power } \\
\mathrm{mJ}\end{array}$ & $\begin{array}{r}\lambda_{2} \text { power } \\
\mathrm{mJ}\end{array}$ & Rep. rate & $\begin{array}{r}{[\mathrm{Hg}]} \\
\mathrm{ng} \mathrm{m}^{-3}\end{array}$ & $\begin{array}{r}\text { Detection sensitivity (10 s) } \\
\mathrm{pg} \mathrm{m}^{-3}\end{array}$ \\
\hline 407.8 & 0.6 & 4 & 10 & 2.5 & 30 \\
313.2 & 1 & 2 & 10 & 2.5 & 15 \\
313.2 & 0.7 & 0.2 & 50 & 2.5 & 35 \\
\hline
\end{tabular}

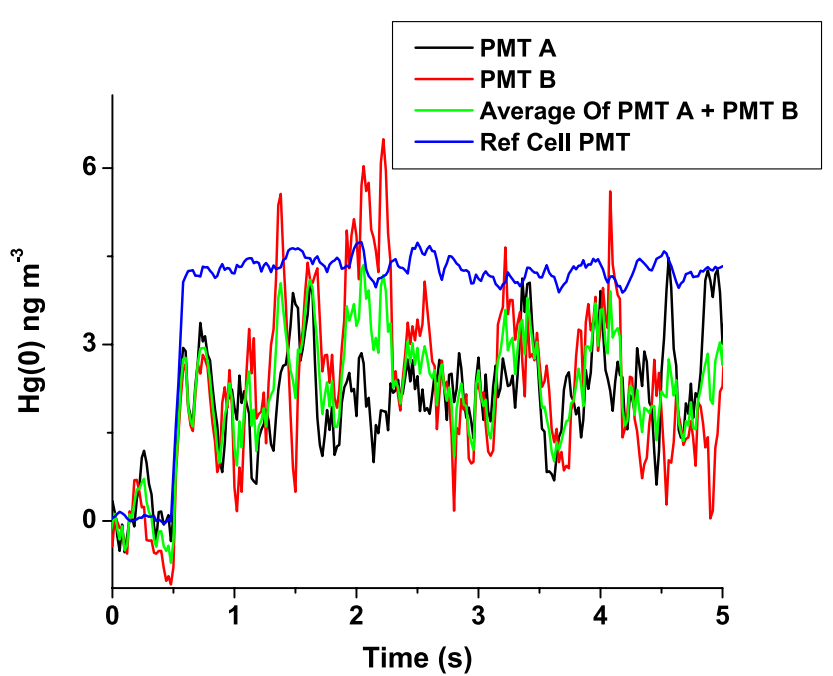

Figure 17. 2P-LIF ambient sample using $50 \mathrm{~Hz}$ laser system, taking 5 -shot averages to give an effective sampling time of $10 \mathrm{~Hz}$. The figure shows a $5 \mathrm{~s}$ slice of data giving the outputs of PMT A, PMT $\mathrm{B}$, their average and the reference cell.

The figure shows a $5 \mathrm{~s}$ slice of data giving the outputs of PMT A, PMT B, their average and the reference cell. We see rapid variation in the ambient signal that is not present in the reference cell signal, indicating that these fluctuations are not due to instrumental artifacts. However, we again see that some of the fluctuations are not correlated between the two PMTs, suggesting that the fluctuations are, at least in part, a reflection of the photon statistics. We believe that a significant increase in the power of the $313.2 \mathrm{~nm}$ excitation beam is possible and that we can also increase the number of detection PMTs to increase the number of photons collected and improve the photon statistics.

\subsection{Detection sensitivity}

We have used the $253.7 \mathrm{~nm} / 407.8 \mathrm{~nm}$ detection at $10 \mathrm{~Hz}$ and the $253.7 \mathrm{~nm} / 313.2 \mathrm{~nm}$ excitation scheme with both the 10 and $50 \mathrm{~Hz}$ laser systems. The use of the $50 \mathrm{~Hz}$ system in the mobile laboratory is somewhat more challenging because of the sensitivity of the Nd:YAG pump laser to temperature fluctuations. In addition, we have relatively limited experience in the use of the PDL dye lasers with $50 \mathrm{~Hz}$ pumping and we saw a very large decrease in the output power at
$313.2 \mathrm{~nm}$ as compared to the decrease at $253.7 \mathrm{~nm}$. Table 1 shows an example of the limits of detection (LODs) that we have achieved through examination of the $10 \mathrm{~Hz}$ data from RAMIX with $253.7 \mathrm{~nm} / 407.8 \mathrm{~nm}$ excitation and using both 10 and $50 \mathrm{~Hz}$ pump lasers with the $253.7 \mathrm{~nm} / 313.2 \mathrm{~nm}$ excitation scheme with the mobile laboratory located at RSMAS close to Biscayne Bay. The analysis examined blocks of data that were taken contiguously with typically $5-10 \mathrm{~min}$ of signal with $1 \mathrm{~min}$ of background sampling before and after. The LOD is a $2 \sigma$ measure of the standard deviation in the background scatter. The limits of detection we have achieved with the $313.2 \mathrm{~nm}$ scheme are comparable to those achieved using $407.8 \mathrm{~nm}$. As a practical matter, the advantages associated with the use of a red dye in methanol solution with a long lifetime compared with the use of an Exalite dye in dioxane solution are significant and outweigh the disadvantage of having to frequency-double. The detection limits we have achieved after a relatively short period of time are comparable to those achieved with the $407.8 \mathrm{~nm}$ system after several years of development. At the moment, the large drop in $313.2 \mathrm{~nm}$ power associated with the switch to $50 \mathrm{~Hz}$ pumping is significantly limiting our detection sensitivity, and we expect to achieve a considerable gain in sensitivity if we can improve the $313.2 \mathrm{~nm}$ output.

\section{Measurement of total gaseous and reactive gaseous mercury}

It is worth noting that the detection sensitivities achieved here suggest that adding a second analysis cell and using pyrolysis to measure TGM could allow us to measure RGM by difference with sufficiently high sensitivity to make ambient measurements if we average for $30 \mathrm{~s}$. We made preliminary measurements of TGM using pyrolysis during RAMIX, and these measurements will be described elsewhere.

\section{Comparison with other techniques}

As noted above, CVAFS techniques are currently the standard approach to the measurement of $\operatorname{Hg}(0)$ and TGM. As has been discussed by Gustin and Jaffe (2010), the extent to which CVAFS systems measure some fraction of RGM is an issue that requires resolution. However, it is clear that these systems require preconcentration and are not capable of fast 
in situ determination of $\operatorname{Hg}(0)$. Pierce et al. (2013) provide a review of CRDS and other mercury sensors that might offer an alternative to CVAFS. Faïn et al. (2010) proposed that CRDS is capable of fast in situ measurements and reported a detection sensitivity of $0.1 \mathrm{ng} \mathrm{m}^{-3}$ with a $10 \mathrm{~s} \mathrm{time} \mathrm{resolu-}$ tion. In more recent work, the same group appears to have acknowledged that, because of $\mathrm{O}_{3}$ interference, in situ measurements of $\operatorname{Hg}(0)$ are not feasible using CRDS and that the sample needs to be stripped of ozone before introduction into the CRDS cavity (Pierce et al., 2013). Under these conditions they report a detection sensitivity of $0.35 \mathrm{ng} \mathrm{m}^{-3}$ with an integration time of $5 \mathrm{~min}$. The ozone is stripped from the ambient sample by pyrolysis, which may convert RGM to $\mathrm{Hg}(0)$; therefore any RGM must be removed before pyrolysis. It appears that the CRDS technique is not capable of the sensitivity and time resolution currently achievable with CVAFS instruments, and it is unlikely to be useful for fast in situ measurements of $\mathrm{Hg}(0)$ at typical ambient levels.

\section{Conclusions}

We have described the deployment of a laser-based sensor for gas-phase elemental mercury that has high sensitivity and fast temporal resolution. The sensor can be deployed for in situ measurements in the open atmosphere with essentially no perturbation of the environment. An ambient sample can also be pulled through a fluorescence cell, allowing for standard addition calibrations of the concentration. No type of preconcentration is required, and there appear to be no significant interferences from other atmospheric constituents, including gas-phase oxidized mercury species. As a consequence, it is not necessary to remove RGM from the sample. Currently achievable detection sensitivity is $\sim 15 \mathrm{pg} \mathrm{m}^{-3}$ $\left(\sim 5 \times 10^{4}\right.$ atoms cm $\left.\mathrm{cm}^{-3}, \sim 2 \mathrm{ppq}\right)$ with a 10 s detection time. The instrument has operated with an effective time resolution of $10 \mathrm{~Hz}$, but additional work is required to produce the precision necessary to perform eddy correlation measurements. Addition of a pyrolysis channel should allow for the measurement of TGM and hence RGM (by difference) with good sensitivity and time resolution.

Acknowledgements. This work was supported through a National Science Foundation Major Instrumental Grant (\#MRI-0821174), through NSF grant \# AGS-1101965 and by the Electric Power Research Institute. We thank Mae Gustin and her research group for their hospitality and assistance during the RAMIX intercomparison.

Edited by: D. Heard

\section{References}

Bauer, D., Campuzano-Jost, P., and Hynes, A. J.: Rapid, ultrasensitive detection of gas phase elemental mercury under atmospheric conditions using sequential two-photon laser induced fluorescence, J. Environ. Monitor., 4, 339-343, 2002.

Bauer, D., D'Ottone, L., Campuzano-Jost, P., and Hynes, A. J.: Gas Phase Elemental Mercury: A Comparison of LIF Detection Techniques and Study of the Kinetics of Reaction with the Hydroxyl Radical, J. Photochem. Photobiol. A, 157, 247-256, doi:10.1016/S1010-6030(03)00065-0, 2003.

Breckenridge, W. H. and Umemoto, H.: Collisional Quenching of Electronically Excited Metal Atoms, in Advances in Chemical Physics: Dynamics of the Excited State, Volume 50, edited by: Lawley, K. P., John Wiley \& Sons, Inc., Hoboken, NJ, USA, doi:10.1002/9780470142745.ch5, 2007.

Creasey, D. J., Heard, D. E., and Lee, J. D.: Absorption crosssection measurements of water vapour and oxygen at $185 \mathrm{~nm}$. Implications for the calibration of field instruments to measure $\mathrm{OH}, \mathrm{HO}_{2}$ and $\mathrm{RO}_{2}$ radicals, Geophys. Res. Lett., 27, 1651, doi:10.1029/1999GL011014, 2000.

Deech, J. S., Pitre, J., and Krause, L.: Quenching and Depolarization of Mercury Resonance, Can. J. Phys., 49, 1976-1981, 1971.

Diez, S.: Human health effects of methylmercury exposure, Rev. Environ. Contam. T., 198, 111-132, doi:10.1007/978-0-38709647-6_3, 2009.

Faïn, X., Moosmüller, H., and Obrist, D.: Toward real-time measurement of atmospheric mercury concentrations using cavity ring-down spectroscopy, Atmos. Chem. Phys., 10, 2879-2892, doi:10.5194/acp-10-2879-2010, 2010.

Finley, B. D., Jaffe, D. A., Call, K., Lyman, S. N., and Gustin, M.: Development, testing, and deployment of an air sampling manifold for spiking elemental and oxidized mercury during RAMIX, Environ. Sci. Technol., 47, 7277-7284, doi:10.1021/es304185a, 2013.

Goldsmith, J. E. M.: Photochemical Effects in $205 \mathrm{~nm}$, Two. Photon-Excited Fluorescence Detection of Atomic Hydrogen. Flames, Opt. Lett., 11, 416-418, 1986.

Gustin, M. and Jaffe, D.: Reducing the Uncertainty in Measurement and Understanding of Mercury in the Atmosphere, Environ. Sci. Technol., 44, 2222-2227, 2010.

Gustin, M. S., Huang, J., Miller, M., Peterson, C., Jaffe, D., Ambrose, J., Finley, B., Lyman, S., Call, K., Talbot, R., Feddersen, D., Mao, H., and Lindberg, S.: Do We Understand What the Mercury Speciation Instruments Are Actually Measuring? Results of RAMIX, Environ. Sci. Technol., 47, 7295-7306, doi:10.1021/es3039104, 2013.

Heard, D. E. and Pilling, M. J.: Measurement of $\mathrm{OH}$ and $\mathrm{HO}_{2}$ in the troposphere, Chem. Rev., 103, 5163-5198, 2003.

Hynes, A. J., Donohoue, D. L., Goodsite, M. E., and Hedgecock, I. M.: Our current understanding of major chemical and physical processes affecting mercury dynamics in the atmosphere and at the air-water/terrestrial interfaces, in: Mercury Fate and Transport in the Global Atmosphere, edited by: Mason, R. and Pirrone, N., Springer Science, 427-457, doi:10.1007/978-0-387-939582_14, New York, NY, 2009.

Landis, M. S., Stevens, R. K., Schaedlich, F., and Prestbo, E. M.: Development and Characterization of an Annular Denuder Methodology for the Measurement of Divalent Inorganic Reac- 
tive Gaseous Mercury in Ambient Air, Environ. Sci. Technol., 36, 3000-3009, 2002.

Maya, J.: Ultraviolet absorption cross sections of $\mathrm{HgI}_{2}, \mathrm{HgBr}_{2}$, and tin (II) halide vapors, J. Chem. Phys., 67, 4976, doi:10.1063/1.434681, 1977.

Mergler, D., Anderson, H. A., Chan, L. H. M., Mahaffey, K. R., Murray, M., Sakamoto, M., and Stern, A. H.: Methylmercury exposure and health effects in humans: A worldwide concern, Ambio., 36, 3-11, 2007.

Michael, J. V. and Suess, G. N.: Absolute Quenching CrossSections of $\mathrm{Hg}\left({ }^{3} \mathrm{P}\right)$ with various molecules, J. Phys. Chem., 78, 482-487, 1974.

Pierce, A., Obrist, D., Moosmüller, H., Faïn, X., and Moore, C.: Cavity ring-down spectroscopy sensor development for high-time-resolution measurements of gaseous elemental mercury in ambient air, Atmos. Meas. Tech., 6, 1477-1489, doi:10.5194/amt-6-1477-2013, 2013.

Subir, M., Ariya, P. A., and Dastoor, A. P.: A review of uncertainties in atmospheric modeling of mercury chemistry I. Uncertainties in existing kinetic parameters : Fundamental limitations and the importance of heterogeneous chemistry, Atmos. Environ., 45, 5664-5676, 2011.

Subir, M., Ariya, P. A., and Dastoor, A. P.: A review of the sources of uncertainties in atmospheric mercury modeling II. Mercury surface and heterogeneous chemistry - A missing link, Atmos. Environ., 46, 1-10, 2012.
UNEP Chemicals Branch: The Global Atmospheric Mercury Assessment: Sources, Emissions and Transport, UNEP-Chemicals, Geneva, Switzerland, 2008.

Templet, P., McDonald, J. R., McGlynn, S. P., Kendrow, C. H., Roebber, J. L., and Weiss, K.: Ultraviolet Absorption Spectra of Mercuric Halides, J. Chem. Phys., 56, 5746, doi:10.1063/1.1677111, 1972.

UNEP: United Nations Environment Program, Chemicals Branch, The Global Atmospheric Mercury Assessment: Sources, Emissions and Transport, ISBN: 978-92-807-3310-5, UNEP Chemicals Branch, Geneva, Switzerland, 2008.

UNEP: Global Mercury Assessment 2013: Sources, Emissions, Releases and Environmental Transport, UNEP Chemicals Branch, Geneva, Switzerland 2013.

UNEP: United Nations Environment Program, available at: http: //www.mercuryconvention.org (last access: 5 November 2014), 2014.

U.S. EPA: United States Environmental Protection Agency "Mercury Research Strategy", EPA/600/R-00/073, September 2000.

U.S. EPA: Memorandum: Emissions Overview: Hazardous Air Pollutants in Support of the Final Mercury and Air Toxics Standard, U.S. EPA, EPA-454/R-11-014, available at: http://www.epa.gov/ mats/pdfs/20111216EmissionsOverviewMemo.pdf (last access: 5 November 2014), 2011. 